\title{
LETTER
}

\section{BRCA mutations in Italian breast/ovarian cancer families}

DOI: $10.1038 /$ sj/ejhg/5200755

Baudi et al. ${ }^{1}$ described the first example of a founder BRCA1 (MIM 113705) mutation specific to the Italian population. They studied 24 patients from unrelated breast/ovarian cancer families from the southern region of Calabria and found the 5083del19 mutation to be present four times. This single mutation accounted for four of the six BRCA1 mutations detected in the study. Haplotype analysis confirms the 5083del19 mutation to be a founder mutation. Here we present data on Italian breast/ovarian cancer families in North America, and ask whether or not this mutation is observed in these families.

Founder mutations in BRCA1 and BRCA2 (MIM 600185) have been described in several Western European countries, but, to date, no population has demonstrated founder effects as striking as those observed for Icelandic and the Ashkenazi Jewish groups. ${ }^{2-4}$ Table 1 summarises the different BRCA1 or BRCA2 mutations that have been reported in more than one family from various studies and regions of Italy. To date, only the BRCA1 5083del19 mutation is recurrent and specific to individuals of Italian descent; most mutations are also found in other European countries.
At the Sunnybrook \& Women's College Health Sciences Centre in Toronto, Canada, we evaluated DNA samples for germline mutations in BRCA1 and BRCA2 from 116 women with primary cancers of the breast or ovary, and with at least one parent with Italian ancestry. The 116 women participated in genetic studies for either clinical (high-risk families) or research (unselected patients) purposes. A variety of methods were employed for mutation analysis. All samples were tested for deleterious mutations in exons 10 and 11 of BRCA2 and exons 2, 5, 11, 16, 20 and exon 13 duplication of BRCA1. This testing covered the majority of mutations described previously for Italian patients (Table 1), revealing 29 of the 39 mutations (Table 2). Subsequent testing by direct sequencing (by Myriad Genetic Laboratories) revealed ten additional mutations in other exons.

Thirty-nine $B R C A 1$ or $B R C A 2$ mutations were identified among the 116 families (33.6\%); 23 in BRCA1 and 16 in $B R C A 2$ (Table 2). In total, 19 of the 39 mutations $(48.7 \%)$ were present in more than one family. Of particular significance was the detection of the BRCA1 exon 16 $5083 d e 119$ in five families. Three of these five families, who

Table 1 BRCA1 and BRCA2 mutations reported in two or more Italian families

\begin{tabular}{|c|c|c|c|c|c|c|}
\hline Mutation & Exon & $\begin{array}{l}\text { No. } \\
\text { families }\end{array}$ & $\begin{array}{l}\text { BIC } \\
\text { entries }\end{array}$ & Reference & Region or center & $\begin{array}{l}\text { Ethnic populations } \\
\text { assciated with mutation }\end{array}$ \\
\hline \multicolumn{7}{|l|}{$B R C A 1$} \\
\hline T300G (C61G) & 5 & 4 & 67 & $1,6,7$ & Calabria, Modena, Central and South & European \\
\hline 1135insA & 11 & 2 & 30 & ${ }^{8}$; our study & Milan & Norwegian, Austrian, French \\
\hline 1479delAG & 11 & 2 & 1 & 5; our study & - & - \\
\hline 1499insA & 11 & 7 & 1 & $8-10$ & Tuscany, Pisa, Milan & - \\
\hline C1806T (Q563X) & 11 & 2 & 37 & 8,11 & Aviano, Milan, North & Swedish, Danish, Dutch, German, Austrian \\
\hline 2846 del 4 & 11 & 3 & 3 & $8,11,12$ & Aviano, Padova, Milan, North & Dutch \\
\hline 3596del4 & 11 & 2 & 2 & 7,12 & Modena & - \\
\hline 3875 del 4 & 11 & 3 & 36 & 5,8 ; our study & Milan & Dutch, Czech \\
\hline G4236T (E1373X) & 12 & 3 & 3 & ; our study & - & - \\
\hline 5083del19 & 16 & 11 & 18 & $1,6,11 ;$ our study & Calabria, Aviano, Central and South & - \\
\hline 3.2kb deletion & 17 & 2 & 1 & & Padova & - \\
\hline 5382insC & 20 & Numerous & 267 & $7,8,11 ;$ our study & Worldwide & Ashkenazi Jewish, European \\
\hline 5438insC & 21 & 2 & 2 & Our study & - & - \\
\hline \multicolumn{7}{|l|}{$B R C A 2$} \\
\hline 5950delCT & 11 & 2 & 13 & 8,14 ; our study & Central and South & French, German \\
\hline 6431 ins A & 11 & 2 & 1 & 15 ; our study & Aviano & - \\
\hline 6696delTC & 11 & 5 & 2 & 6,8 ; our study & Milan, Central and South & - \\
\hline 6819delTG & 11 & 2 & 3 & 5; our study & - & Belgian \\
\hline 8765delAG & 20 & 7 & 17 & & Sardinia & Fr. Canadian, Czech, Yemenite Jewish \\
\hline
\end{tabular}


provided specific information about their ancestry, indicated that they originated from Calabria. The 5083del19 mutation accounted for $21.7 \%$ of all BRCA1 mutations. Seven other mutations were identified in two families each, including the BRCA1 3875del4, 5382insC and the BRCA2 6696delTC previously described in Italian studies. We did not detect two BRCA1 mutations reported in multiple families in Italy (T300G (C61G) and 1499insA).

In a recent study of 649 unselected ovarian cancer patients in Canada, Risch et al. ${ }^{5}$ reported that the highest BRCA mutation frequency $(24.1 \%)$ was among women of Italian ancestry (for non-Jewish subjects). In our study of 116 women of Italian ancestry diagnosed with breast or ovarian cancer, one-third were carriers of mutations in BRCA1 or $B R C A 2$; this mutation frequency is likely an underestimate, as we did not screen all patients for all possible mutations in these genes. In the past, research centres have focused on the exon 11 region of the $B R C A 1$ gene, and interestingly 16 of the 23 BRCA1 mutations identified in Italian families were outside of exon 11. Our data confirms the BRCA1 exon 16 5083del19 mutation to be a founder mutation in the Italian population (from Calabria), in North America as well as in Italy. It may be prudent to screen for recurrent mutations prior to undertaking a full genetic screen in families of Italian origin.

\section{Electronic Database Information}

Accession numbers and URLs for data in this article are as follows:

Table 2 Characteristics of 23 BRCA1 and 16 BRCA2 families of Italian ancestry

\begin{tabular}{|c|c|c|c|c|c|c|}
\hline Familiesì & Exon & Mutation & BIC entries & $\begin{array}{l}\text { Breast } \\
\text { total }\end{array}$ & $\begin{array}{l}\text { Cancer } \\
\leqslant 50\end{array}$ & $\begin{array}{l}\text { Ovarian cancer* } \\
\text { total }\end{array}$ \\
\hline \multicolumn{7}{|l|}{$B R C A 1$} \\
\hline 9080 & 8 & 633delC & 8 & 4 & 4 & 0 \\
\hline 270 & 11 & 1135 ins A & 30 & 2 & 1 & 1 \\
\hline 1024 & 11 & 1479delAG & 1 & 1 & 1 & 3 \\
\hline 10566 & 11 & 1479delAG & 1 & 1 & 1 & 1 \\
\hline $99-021$ & 11 & G3519T (E1134X) & 2 & 2 & 2 & 5 \\
\hline 6880 & 11 & $\mathrm{C} 3726 \mathrm{~T}$ & - & 6 & 5 & 0 \\
\hline 10411 & 11 & 3875delGTCT & 36 & 0 & 0 & 1 \\
\hline 10987 & 11 & 3875delGTCT & 36 & 0 & 0 & 2 \\
\hline 103 & 12 & 4280delTC & 1 & 5 & 4 & 0 \\
\hline 10665 & 12 & G4236T (E1373X) & 3 & 6 & 4 & 1 \\
\hline 0132 & 12 & G4236T (E1373X) & 3 & 2 & 1 & 1 \\
\hline 1231 & 14 & G4603T (R1495M) & 7 & 0 & 0 & 2 \\
\hline 2770 & 16 & C4808G (Y1563X) & 18 & 14 & 12 & 3 \\
\hline 6716 & 16 & 5083del19 & 18 & 3 & 3 & 2 \\
\hline 444 & 16 & 5083del19 & 18 & 2 & 2 & 1 \\
\hline 9098 & 16 & 5083del19 & 18 & 6 & 6 & 1 \\
\hline 9305 & 16 & 5083del19 & 18 & 6 & 5 & 8 \\
\hline 1525 & 16 & 5083del19 & 18 & 1 & 1 & 2 \\
\hline 9327 & 18 & 5225delA & - & 3 & 3 & 1 \\
\hline 3574 & 20 & 5382insC & 267 & 3 & 3 & 1 \\
\hline 166 & 20 & 5382insC & 267 & 6 & 2 & 4 \\
\hline 2973 & 21 & 5438insC & 2 & 6 & 4 & 5 \\
\hline 202 & 21 & 5438insC & 2 & 15 & 6 & 7 \\
\hline \multicolumn{7}{|l|}{$B R C A 2$} \\
\hline 3694 & 9 & 924delT & - & 7 & 6 & 0 \\
\hline 11761 & 10 & 1538 del 4 & 1 & 1 & 0 & 1 \\
\hline 9711 & 10 & 2024del5 & 5 & 4 & 4 & 1 \\
\hline 9052 & 10 & 2034delA & 5 & 4 & 2 & 0 \\
\hline 9822 & 11 & 2331delTATT & 1 & 1 & 2 & 0 \\
\hline 002 & 11 & 3036delACAA & 24 & 4 & 4 & 2 \\
\hline 10051 & 11 & 4510insT & - & 1 & 1 & 1 \\
\hline 1703 & 11 & 5302insA & 1 & 0 & 0 & 1 \\
\hline 9098 & 11 & 5950delCT & 13 & 2 & 2 & 1 \\
\hline 0510 & 11 & C6137A (S1970X) & 1 & 5 & 3 & 1 \\
\hline 1885 & 11 & 6431 ins $A$ & 1 & 4 & 2 & 0 \\
\hline 7001 & 11 & 6696delTC & 2 & 2 & 2 & 1 \\
\hline 1777 & 11 & 6696delTC & 2 & 6 & 3 & 0 \\
\hline 071 & 11 & 6819delTG & 3 & 2 & 2 & 0 \\
\hline 11493 & 11 & 6819delTG & 3 & 0 & 0 & 1 \\
\hline 9207 & 26 & G9800A (W3191X) & - & 7 & 7 & 0 \\
\hline
\end{tabular}

*Includes fallopian tube cancers; †Five-digit family numbers indicate unselected patients with ovarian cancer, as described by Risch et al. ${ }^{5}$ 
Online Mendelian Inheritance in Man (OMIM), http:// www3.ncbi.nlm.nih.gov/Omim/, for inherited breast cancer type 1 and ovarian cancer [MIM 113705] and for inherited breast cancer type 2 [MIM 600185].

Breast Cancer Information Core Database (BIC), http://www.nhgri.nih.gov/Intramural_research/Lab_transfer/ Bic/, for information on sequence alterations in BRCA1 and $B R C A 2$.

\section{Acknowledgments}

We thank the Familial Ovarian Tumour Study group (FOTS: Risch et al 2001) for contributing data for this report. Alexander Liede's doctoral studies are supported by the Canadian Institutes of Health Research (formerly MRC).

Raluca Nedelcu ${ }^{\dagger}$ Department of Clinical Cancer Genetics, City of Hope Comprehensive Cancer Center, 1500 East Duarte Road, Duarte, California, CA 91010, USA

Alexander Liede ${ }^{* \dagger}$, Jennifer Aubé, Amy Finch, Elaine Kwan, Elaine Jack, Steven A Narod Centre for Research in Women's Health, Sunnybrook and Women's College Health Sciences Centre, 790 Bay Street, Suite 750A, Toronto, Ontario, ON M5G 1N8, Canada

Susan Randall, Lara Hugel, Katherine Clark Familal Ovarian Cancer Clinic, Department of Gynecologic Oncology, Princess Margaret Hospital, 610 University Avenue, M-704, Toronto, Ontario, ON M5G 2M9, Canada

${ }^{*}$ Correspondence: Alexander Liede, Centre for Research in Women's Health, Sunnybrook and Women's College Health Sciences Centre, 790 Bay Street, Suite 750A, Toronto, Ontario, ON M5G 1N8, Canada. Tel: +1 416351 3765; Fax: +1 416351 3767; E-mail: alex.liede@swchsc.on.ca

${ }^{\dagger}$ These authors contributed equally to this study

\section{References}

1 Baudi $\mathrm{F}$ et al: Evidence of a founder mutation of BRCA1 in a highly homogeneous population from southern Italy with breast/ovarian cancer. Hum Mutat 2001; 18:163 - 164 .

2 Johannesdottir G et al: High prevalence of the 999del5 mutation in Icelandic breast and ovarian cancer patients. Cancer Res 1996; 56: $3663-3665$

3 Struewing JPet al: The carrier frequency of the BRCA1 185delAG mutation is approximately 1 percent in Ashkenazi Jewish individuals. Nature Genet 1995; 11: 198-200.

4 Roa BB et al: Ashkenazi Jewish population frequencies for common mutations in BRCA1 and BRCA2. Nature Genet 1996; 14: $185-7$.

5 Risch HA et al: Prevalence and penetrance of germline BRCA1 and BRCA2 mutations in a population series of 649 women with ovarian cancer. Am J Hum Genet 2001; 68: 700-710.

6 Ottini L et al: BRCA1 and BRCA2 mutations in central and southern Italian patients. Breast Cancer Res 2000; 2: 307 - 710.

7 Turchetti D et al: BRCA1 mutations and clinicopathological features in a sample of Italian women with early-onset breast cancer. Eur J Cancer 2000; 36: 2083 - 2089.

8 De Benedetti VM et al: Characterization of ten novel and 13 recurring BRCA1 and BRCA2 germline mutations in Italian breast and/or ovarian carcinoma patients. Mutations in brief no. 178. Online. Hum Mutat 1998; 12: 215.

9 Caligo MA et al: BRCA1 germline mutational spectrum in Italian families from Tuscany: a high frequency of novel mutations. Oncogene 1996; 13: 1483-1488.

10 De Benedetti VM et al: Screening for mutations in exon 11 of the BRCA1 gene in 70 Italian breast and ovarian cancer patients by protein truncation test. Oncogene 1996; 13: 1353-1357.

11 Santarosa $\mathrm{M}$ et al: Low incidence of BRCA1 mutations among Italian families with breast and ovarian cancer. Int J Cancer 1998; 78: $581-786$.

12 Montagna $\mathrm{M}$ et al: Identification of seven new BRCA1 germline mutations in Italian breast and breast/ovarian cancer families. Cancer Res 1996; 56: 5466-5469.

13 Montagna $\mathrm{M}$ et al: Identification of a $3 \mathrm{~kb}$ Alu-mediated BRCA1 gene rearrangement in two breast/ovarian cancer families. Oncogene 1999; 18: 4160-4165.

14 Ottini L et al: Novel deletion at codon 1254 of the BRCA1 gene in an Italian breast cancer kindred. Hum Mutat 1998; Suppl: S237-S239.

15 Santarosa M et al: BRCA1 and BRCA2 genes: role in hereditary breast and ovarian cancer in Italy. Int J Cancer 1999; 83: 5 -9.

16 Pisano $\mathrm{M}$ et al: Identification of a founder BRCA2 mutation in Sardinia. Br J Cancer 2000; 82: 553-559. 